\title{
WATER VERSUS LACTOSE SOLUTION AS A DISPERSION MEDIUM FOR PARTICLE ANALYSIS IN SWEETENED CONDENSED MILK BY LASER DIFFRACTION
}

\author{
João Pablo F. Pereira ${ }^{\mathrm{a}, *,(\mathbb{D}}$, Igor L. de Paula ${ }^{\mathrm{b}}$, Rodrigo Stephani ${ }^{\mathrm{b}}$, Ítalo T. Perrone ${ }^{\mathrm{c}}$, Luiz Fernando C. de Oliveira ${ }^{\mathrm{b}}$ and \\ Antonio F. de Carvalho ${ }^{\mathrm{a}}$

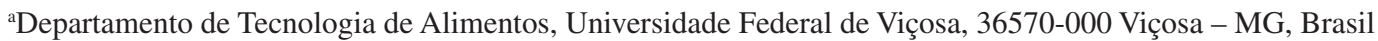 \\ 'Departamento de Química, Instituto de Ciências Exatas, Universidade Federal de Juiz de Fora, 36036-900 Juiz de Fora - MG, Brasil \\ 'Departamento de Ciências Farmacêuticas. Universidade Federal de Juiz de Fora, 36036-900 Juiz de Fora - MG, Brasil
}

Recebido em 27/05/2019; aceito em 24/07/2019; publicado na web em 30/08/2019

\begin{abstract}
Sweetened condensed milk contains various dispersed particles, such as proteins, fats, and lactose, all of which make it highly viscous. During sweetened condensed milk production, microcrystalline lactose is added in order to control the product crystallization. The purpose of this study was to characterize the behavior of commercially sold sweetened condensed milks submitted to laser particle size analysis using two different dispersion media: water and a lactose solution. The lactose solution dispersion medium extended the length of time the sweeten condensed milk samples' original characteristics were present during the laser diffraction particle sizing measurements that were carried out. Significant difference was observed $(\mathrm{p}<0.05)$ between analysis times when water was used as a dispersing medium versus when a lactose solution was used $(\mathrm{p}>0.05)$. Using a lactose solution as a dispersion medium when determining particle size in sweetened condensed milk prolongs the original characteristics of the sample substance during laser diffraction particle analysis.
\end{abstract}

Keywords: concentrated dairy products; particle size; characterization.

\section{INTRODUCTION}

Laser diffraction particle analysis is a technique which involves dispersing a sample in a flowing liquid or it could be done by dry via. The particles cause discontinuities in the fluid flow which are detected by an incident laser, and correlated with particle size. ${ }^{1}$ Once a certain number of particles is reached, the incident light undergoes different phenomena (diffraction, refraction, reflection and absorption) which in turn create a three-dimensional light envelope. ${ }^{2}$ The detectors measure the intensity and the angle of scattered light, then use mathematical algorithms to convert the signal to particle size. ${ }^{1}$ Prior knowledge of the sample matter's refractive indexes is necessary in order to analyze the dispersant medium. Laser diffraction analysis is non-specific and the particle distribution present in the samples is determined by grouping the particles by size rather than chemical composition or other segregation criteria. This technique is widely used in food matrix studies, as preparation of size-controlled starch nanoparticles, characterizations of emulsions, studies of the presence of micro- and nanoparticles in drinks and foods and quantitative determination of fat and total protein. ${ }^{3-7}$

Codex Alimentarius defines sweetened condensed milks as dairy products that can be obtained by partially removing water from a milk and sugar solution or any other process that produces a product with the same composition and characteristics. The product must present

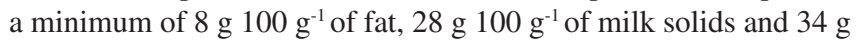
$100 \mathrm{~g}^{-1}$ of protein in non-fatty milk solids. ${ }^{8}$

Sweetened condensed milk contains dispersed proteins, fats, and lactose which give it a high viscosity.

The lactose content in commercial sweetened condensed milk

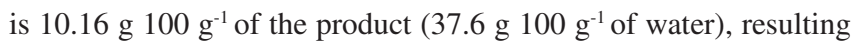
a saturated solution of lactose in water. ${ }^{9}$ When lactose is present in the solution in excess of 2.1 times the saturation value $\left(20{\mathrm{~g} 100 \mathrm{~g}^{-1}}^{-}\right.$ water at $20^{\circ} \mathrm{C}$ ), spontaneous crystallization occurs. ${ }^{10}$ Determining the

*e-mail: joaopablo_fp@yahoo.com.br number of nuclei formed or induced during lactose crystallization is important in order to control crystal growth up until the sugar supersaturation decreases. The available surface area for deposition, viscosity, temperature and mutarotation are also factors that affect crystal growth. ${ }^{11}$ Controlling the size of lactose crystals during crystallization in sweetened condensed milk is important in order to obtain a product with desirable sensorial characteristics. Laser particle analysis can be used to determine crystal size during production and shelf storage when certain conditions have been established. The usual liquid for particle size determination in foods is water, the hypothesis of this work is: for sugar crystallized foods solubilization would happens during analysis affecting the results. The aim of the present work was to characterize the behavior of commercially distributed sweetened condensed milk samples via laser diffraction analysis using different dispersant media (water and lactose solution) and determine the influence of solubilization time on the distribution size of particles.

\section{EXPERIMENTAL}

Samples from four different brands of sweetened condensed milk purchased in Juiz de Fora, MG, Brazil were analyzed gravimetrically for moisture content, by Kjeldahl method (the total nitrogen in the samples was determined in duplicate, and the nitrogen content was multiplied by the conversion factor 6.38 to obtain the equivalent amounts of protein) ${ }^{12}$ for protein content and using the Gerber method (based in acid digestion coupled to centrifugal separation in specific laboratory glassware ${ }^{13}$ for fat content. The content of the fixed mineral residue (FMR) was determined gravimetrically by incinerating the sample in a muffle oven at $550{ }^{\circ} \mathrm{C}$ for 10 hours. ${ }^{14}$ Sugar content (sucrose and lactose) was obtained by mathematical calculation.

Microphotographs of the samples were taken with an Olympus BX51 optical microscope equipped with a bright halogen light source. Average crystal size was determined using OPUS software. The crystals in the images were counted to calculate the number of crystals present per gram of sweetened condensed milk. In total, 
60 micrographs were taken for each sample (six slides x 10 fields per slide). ${ }^{15}$

Particle size distribution during the dissolution of the sweetened condensed milk samples was determined using a Beckman Coulter LS 13320 Particle Sizing Analyzer (Beckman Coulter, Miami, FL, USA) coupled to a liquid module (Beckman Coulter, Miami, FL, USA).

Approximately one drop of each sample was added to the liquid module filled with room temperature water to facilitate $47 \pm 5 \%$ of obscuration in the PIDS (Polarization Intensity Differential Scattering System) photo detectors. The dissolution process was monitored over an eight minutes period and measured every two minutes for a total of five successive measurements. Samples of the same five sweetened condensed milk brands were submitted to the same procedure and conditions using a lactose solution instead of water in the liquid module (necessary adjustments to the apparatus were made). The lactose solution was prepared with a concentrated solution of lactose $23.0 \%$ w/w, cooled to $25^{\circ} \mathrm{C}$, filtered, then added to the water in the analyzer reservoir to obtain a concentration of $13.0 \pm 0.5 \% \mathrm{w} / \mathrm{w}$ lactose (to approximate the sample lactose). Approximately 750 $\mathrm{mL}$ of concentrated solution was used to test each sample. Data were collected at 0.04 to $2000 \mu \mathrm{m}$ for 90 seconds. The results were obtained using the standard refractive index of the dispersing medium (1.332 water) or (1.352 lactose solution) and the lactose particle refractive index (1.53). ${ }^{16}$

Statistical analyzes were performed using Graph Pad Prism 5 software (Graph Pad Software Inc., San Diego, CA, USA). For the treatment variable (water or lactose solution), the Student's t-test was performed simultaneously. For the time variable, a one-way analysis of variance was performed followed by verification using the Tukey test.

\section{RESULTS}

The results of the centesimal composition of the market sweetened condensed milks tested are described in Table 1.

Table 1. Composition of sweetened condensed milk $(n=4)$

\begin{tabular}{lcccc}
\hline Attribute & Mean & $\begin{array}{c}\text { Standard } \\
\text { Deviation }\end{array}$ & $\begin{array}{c}\text { Standard } \\
\text { Error }\end{array}$ & $\begin{array}{c}\text { Variation } \\
\text { Coefficient } \\
(\%)\end{array}$ \\
\hline Moisture $\left({\left.\mathrm{g} 100 \mathrm{~g}^{-1}\right)}^{27.83}\right.$ & 0.61 & 0.30 & 2.18 \\
Fat $\left(\mathrm{g} 100 \mathrm{~g}^{-1}\right)$ & 7.92 & 0.32 & 0.16 & 3.99 \\
Protein $\left({\left.\mathrm{g} 100 \mathrm{~g}^{-1}\right)}^{6.13}\right.$ & 0.30 & 0.15 & 4.93 \\
FMR $\left({\left.\mathrm{g} 100 \mathrm{~g}^{-1}\right)}\right.$ & 1.30 & 0.12 & 0.06 & 9.32 \\
Sugars $\left({\left.\mathrm{g} 100 \mathrm{~g}^{-1}\right)}^{5}\right.$ & 56.83 & 0.43 & 0.22 & 0.76 \\
\hline
\end{tabular}

Based on the data obtained, it is worth noting product composition standardization for the five sweetened condensed milk samples tested. Composition is just one quality attribute in the production of sweetened condensed milk. Viscosity, flavor, odor, and crystal size are other important quality attributes in commercially-sold sweetened condensed milks. ${ }^{10}$ The data in this study corroborated the results obtained by others works..$^{9,17}$ In the latter study, the centesimal composition of 27 samples of sweetened condensed milk produced in Brazil and 12 samples commercialized in Bangladesh, respectively were evaluated.

The results along with average crystal size are presented in Table 2.

An inverse relationship between number and mean size of the crystals is expected for sweetened condensed milk. ${ }^{10}$ Lactose crystallization takes place due to nucleation crystal growth. During
Table 2. Number and average size of sweetened condensed milk sample lactose crystals

\begin{tabular}{lcc}
\hline Sample & Amount $\left(\mathrm{n}^{\circ}\right.$ crystals g-1 $)$ & Size $(\mu \mathrm{m})$ \\
\hline $\mathrm{a}$ & $1.23 \times 10^{8} \pm 2.14 \times 10^{6}$ & $11.2 \pm 0.6$ \\
$\mathrm{~b}$ & $1.74 \times 10^{8} \pm 1.96 \times 10^{6}$ & $11.1 \pm 0.3$ \\
$\mathrm{c}$ & $1.07 \times 10^{9} \pm 2.87 \times 10^{7}$ & $9.8 \pm 0.8$ \\
$\mathrm{~d}$ & $9.29 \times 10^{8} \pm 1.44 \times 10^{6}$ & $8.8 \pm 1.4$ \\
\hline
\end{tabular}

nucleation, lactose molecules organize and aggregate in order to minimize chemical potential in the solution and balance interfacial tension caused by crystal formation in the new phase. During the crystal growth stage, small particles cluster and/or $\alpha$-lactose molecules bind to the formed nuclei causing them to grow. ${ }^{18}$ In the present study, it is not possible to conclude that the reduced size of certain sample crystals was due to the greater number of nuclei present because the samples have been manufactured for commercial sale and the technology used (addition or not of cores by dispersion and, if added, in what quantity) is not known. However, based on the low standard deviation found the sugar contents of the samples, it can be assumed that the correlation may be true.

As to particle size distribution throughout dissolution time, the dissolution profile difference is shown in the Figure 1.

The value of $\mathrm{d}_{90}$ shows the maximum particle size and represents $90 \%$ of the volume percentage distribution in the sweetened condensed milk samples during laser diffraction particle analysis.

For most of the sweetened condensed milk samples studied, a significant difference was observed $(\mathrm{p}<0.05)$ between analysis times when water was used as a dispersing medium versus when a lactose solution was used ( $p>0.05$ ). The first two reading of sample particle solubility/dispersion in water ( 0 minutes and 2 minutes $)$ were emphasized. There was no difference $(\mathrm{p}>0.05)$ between the measurements performed at 6 and 8 minutes for any of the sweetened condensed milk samples studied. Analysis performed immediately after adding the sample hinders the ability to perform subsequent readings because of the short particle dispersion time. To ensure reliability, the sample needs to be recirculated, regardless of the liquid used for sample dispersion. Therefore, the first laser diffraction particle analysis must be performed after 2 minutes of sample recirculation. Even though non-specified particles, such as the sweetening components, in sweetened condensed milk present a complex analysis matrix and the particle distribution of other components are affected during recirculation, the lactose molecules in the solution play a key role in laser diffraction particle analysis.

The addition of a lactose solution as a dispersion medium promoted disturbances that differ from those found when water was used. The water can be substituted for a lactose solution in order to preserve the crystallized lactose present in the samples and in tern determine particle size. The initial analysis (when the sample profile is as close as possible to the original sample with no dispersant effect) was used to plot the dissolution profile of the samples at 0 and 8 minutes and the final analysis after the dispersion medium had had a maximum effect on the sample.

Using lactose solution instead of water as dispersing medium allowed for a slower dissolution of the analyzed substance and thus a more reliable measurement of particle size in the substance's natural state. The $\mathrm{d}_{90}$ in Figure 1 shows particle size at $90 \%$ distribution per volume (this was higher when measured using a lactose solution); it comes to an approximation of "natural" conditions of the matrices obtained. How concentration differences affect rates of matter migration has been widely demonstrated for different food matrices in scientific studies. ${ }^{19-21}$ 
I
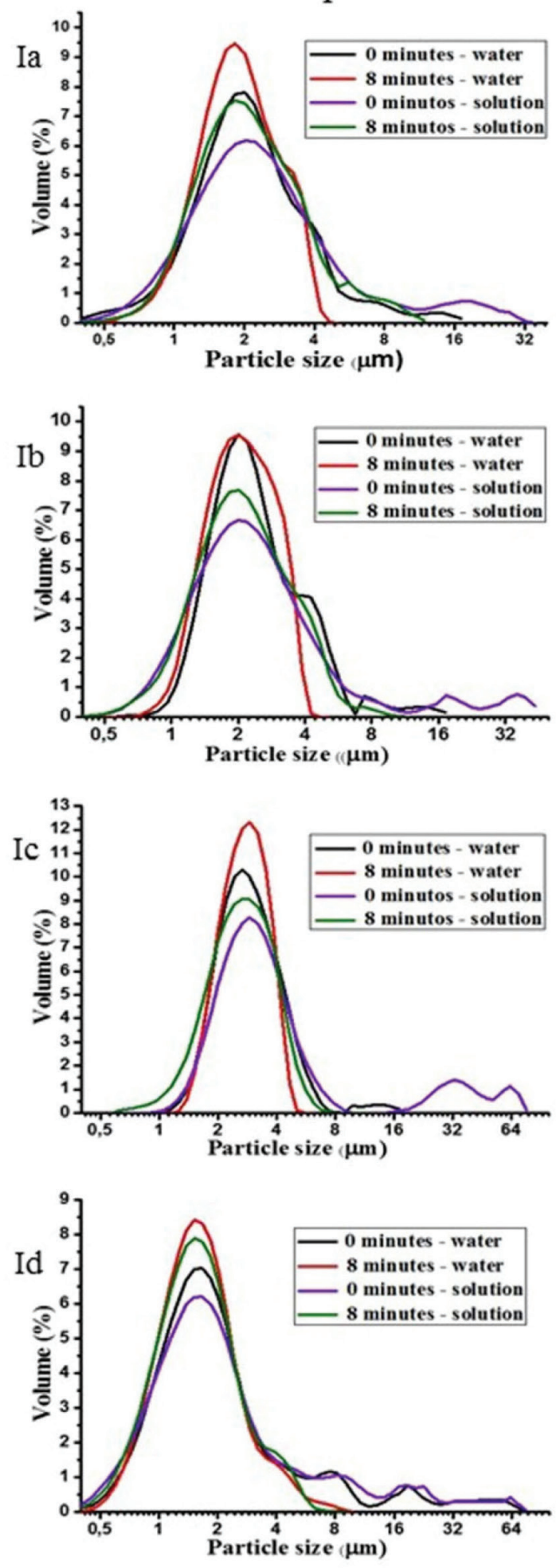

II
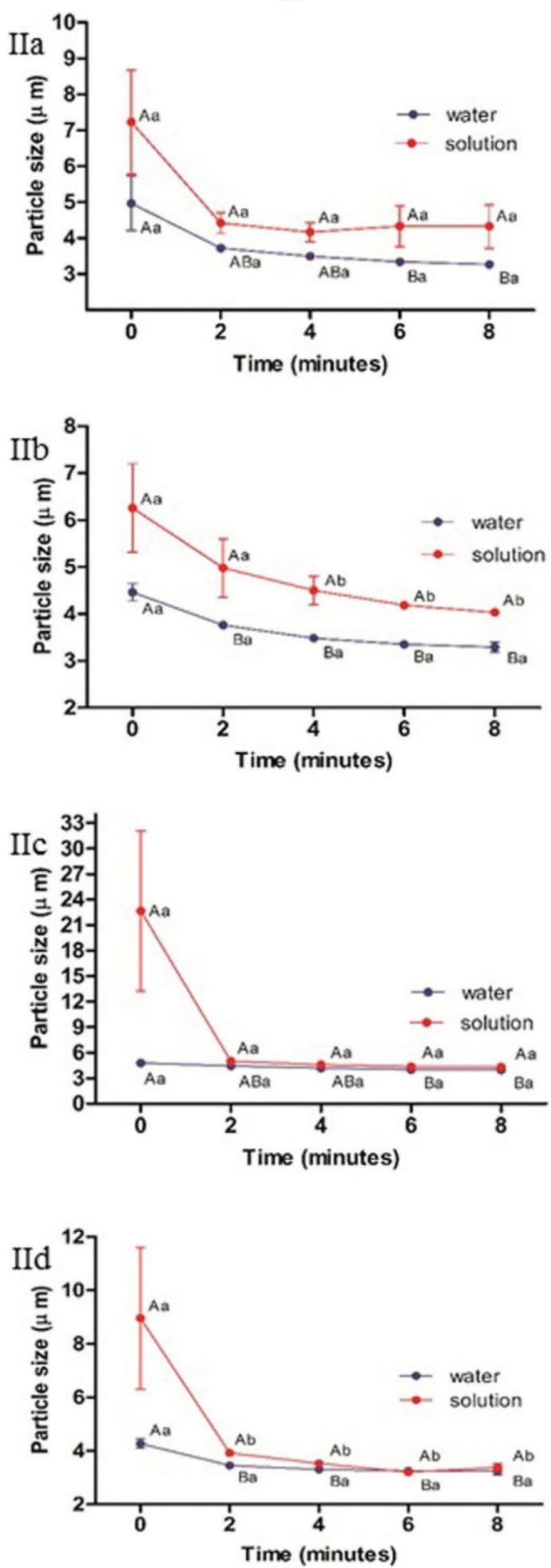

Figure 1. (I) Graphs of particle size distribution mean in sweetened condensed milk samples (Ia, Ib, Ic and Id), analyses carried out at 0 and 8 minutes when samples were dispersed in water and in lactose solution. (II) Particle size distribution ( $d_{90}$ ) of the sweetened condensed milk samples (IIa, IIb, IIc and IId) over five successive measurements $(0,2,4,6$ and 8 minutes). The results are presented by mean \pm standard error of the mean. Means followed by the same capital letter do not differ within the same treatment for the variable time, as determined by one-way variance analysis using the Tukey test $(p>0.05)$. Means followed by the same lowercase letter do not differ within the same time for period the treatment variable, as determined by the Student's t-test ( $p>0.05$ )

\section{CONCLUSIONS}

Using a lactose solution as a dispersion medium when determining particle size in sweetened condensed milk prolongs the original characteristics of the sample substance during laser diffraction particle analysis. Samples dissolve faster when water is used as the dispersant. For greater reliability of results, a two-minute recirculation of the product in the analyzer is necessary. The laser 
diffraction particle analyzer is an important complementary tool for studying particle behavior in the product. The adoption of the methodology studied in this article by the food industry needs more studies because sweetened condensed milk varies significantly in composition and in technologies of production.

\section{ACKNOWLEDGEMENTS}

The authors acknowledge financial support from the following Brazilian agencies: Fundação de Amparo à Pesquisa do Estado de Minas Gerais (Fapemig), Coordenação de Aperfeiçoamento de Pessoal de Nível Superior (CAPES) and Conselho Nacional de Desenvolvimento Científico e Tecnológico (CNPq).

\section{REFERENCES}

1. Brar, S. K.; Verma, M.; Trends Anal. Chem. 2011, 30, 4.

2. Jillavenkatesa, A.; Dapkunas, S. J.; Lum, L. S. H.; Particle Size Characterization, Special Publication 960-1, Government Printing Office: Washington, 2001.

3. Bogomolov, A.; Dietrich, S.; Boldrini, B.; Kessler, R. W.; Food Chem. 2012, 134, 412 .

4. Chang, Y.; Yan, X.; Wang, Q.; Ren, L.; Tong, J.; Zhou, J.; Food Chem. 2017, 227, 369.

5. Ge, S.; Xiong, L.; Li, M.; Liu, J.; Yang, J.; Chang, R.; Liang, C.; Sun, Q.; Food Chem. 2017, 234, 339.

6. De La Calle, I.; Menta, M.; Klein, M.; Séby, F.; Food Chem. 2018, 266, 133.
7. Hart, S. M.; Lin, X. L.; Thilakarathna, S.; Wright, A. J.; Food Chem. 2018, 260, 145.

8. Codex Alimentarius. 1971. Standard 282-1971/rev. 1999. Available at www.fao.org/input/download/standards/173/CXS_282e.pdf, accessed in August 2019.

9. Renhe, I. R. T.; Pereira, D. B. C.; Sá, J. F. O.; Santos, M. C.; Teodoro, V. A. M.; Magalhães, F. A. R.; Perrone, I. T.; Silva, P. H. F.; Food Sci. Technol. 2017, 38, 293.

10. Walstra, P.; Geurts, T. J.; Noomen, A.; Jellema, A.; Boekel, M. A. J. S.; Ciência de la leche y tecnología de los produtos lácteos, Acribia: Zaragoza, 2001.

11. Fox P. F.; McSweeney, P. L. H.; Dairy Chemistry and Biochemistry, $1^{\text {st }}$ ed., Springer: London, 1998.

12. IDF - International Dairy Federation. IDF 20B: Determination of milk proteins, Brussels, 1993.

13. IDF - International Dairy Federation. ISO 488 IDF 105: Milk Determination of fat content - Gerber butyrometers, Brussels, 2008.

14. AOAC International, Official Methods of Analysis, $17^{\text {th }}$ ed., AOAC International: Gaitherburg, 1997.

15. Martinez, E.; Hough, G.; Contarini, A.; J. Dairy Sci. 1990, 73, 612.

16. Mimouni, A.; Schuck, P.; S. Bouhallab, S.; Lait 2005, 85, 253.

17. Siddique, N. A.; Islam, N.; Habib, R.; Rashid, H.; Islam, A.; Afrin, S.; Int. J. Nat. Soc. Sci. 2017, 4, 64.

18. Wong, S. Y.; Hartel, R. W.; J. Food Sci. 2014, 79, 257.

19. Rastogi, N. K.; Raghavarao, K. S. M. S.; J. Food Eng. 1997, 34, 429.

20. Reynier, A.; Dole, P.; Feigenbaum, A.; Food Addit. Contam. 2002, 19, 89.

21. Hartel, R. W.; Ergun, R.; Vogel, S.; Compr. Rev. Food Sci. Food Saf. 2011, 10, 17. 